\title{
America Revisited
}

\author{
By Dr. G. W. C. Kaye, O.B.E.
}

$\mathrm{E}^{\mathrm{N}}$ VEN in depressed times, America is a stimula. ting country to visit, and I found the present national outlook a good deal more subdued than on the occasions of my previous visits; one, ten years ago at the height of a boom period, the other, during the Great War. Even so, the public and industrial activities of the United States seem to have lost little of their customary courage. San Francisco, lacking a site for its projected International Exhibition in 1939, has not hesitated to create one in the shape of an artificial island, some 400 acres in extent, in the middle of the bay. Not content with this, the city has just spent twenty-three million pounds in four years on two large new bridges, one of them, across the Golden Gate, having a record span of 4,200 feet. New York City is building at monumental expense a new elevated high-speed roadway along the water-front of Manhattan Island to try to relieve the traffic congestion, while Los Angeles is constructing road tunnels with the same object.

Americans, one gathers, pride themselves on owning more cars than any other nation. Traffic problems in the big cities are proportionately acute: it appears that on a normal weekday a quarter of a million cars enter New York and leave it, and that in the early afternoon some 35,000 cars are parked in busy streets. Incidentally, no lights are required on cars parked in American streets at night. There are relatively few buses and most of the passenger traffic in New York is carried by the 'subway' (underground). This is cheap ( $2 \frac{1}{2} d$. everywhere), noisy, foul but fast, and the rush-hour scenes are incredible. The elevated railways in both New York and Chicago are an unmitigated eye-sore and a noisesome blight upon the unfortunate streets which hold them.

Thousands of miles of magnificent highways, beautifully graded and cambered, have been built all over the States, largely by 'volunteer' battalions as a palliative for unemployment. Dual tracks and flying junctions lead to high cruising speeds 60 m.p.h. or more seemed to be commonplace. The published annual death-roll from motor accidents in the States is considerably higher than with us it was nearly 40,000 in 1937, that is, nearly twice as large as ours in proportion to the population.

The roads in residential areas gain in attractiveness from the American custom of no fences in front of houses. It follows that there is little or

no privacy in the gardens or "yards", but none is apparently desired. The Americans have a great aptitude for coining words ; 'mortition' I knew of old, but 'beautician' must have come in with the countless beauty parlours.

Continuous demolition and rebuilding and disorganized streets seem to delight the New Yorker, who regards them as a sign of progress and doesn't mind being a little late to-day for the sake of being a little early to-morrow. New Yorkers claim, too, with no apparent contrition, that they possess the noisiest street corner in the world. Public apathy recently helped to terminate the existence of the Noise Abatement Commission. In a room on the sixteenth story, I found the noise of the elevated railway nearby was intolerably loud. On the twenty-seventh story it was beneficial to shut the windows, when telephoning, in order to cut out the rumble of the street traffic.

Most American cities seem to possess skyscrapers, partly in emulation, one supposes, of New York, where the newer skyscrapers are really beautiful by day, and almost fairylike by night when floodlit or when picked out by the lights of the windows of the occupied rooms. I noted, incidentally, that the express elevators usually allowed one second per floor (though sometimes less) whether going up or down. The tall isolated buildings of the new Rockefeller Centre and Radio City, which occupy some 12 acres, arrest attention by their dignified grouping.

Air-conditioning, which one finds in public rooms throughout the States, is a valuable addition to the amenities of railroad travel, particularly in the warmer south. The cooled and filtered air enters from the roofs of the coaches, the chilling being effected either by ice or by refrigerators, and the filtering by asbestos mats or the like. Some of the transcontinental railways run high-speed 'limited' trains on certain days in the week, largely to meet the growing competition of air travel, which is well organized and popular, being well suited to the great distances. In Canada the air carriage of freight, which already greatly exceeds that of any other country, being one third of the total for the world, is acclaimed as an outstanding boon for the widely scattered settlements.

Public interest in scientific matters appears to be high : popular scientific and technical journals of many and varied types cater in abundance on 
the bookstalls for the multitudes of young men who want to make good in the world. Public lectures gather large audiences, and no public dinner or luncheon is apparently complete without a post-prandial lecturer, who will find himself attentively and closely followed. Uplift movements of all kinds receive the enthusiastic support of the women, whose domestic arrangements seem to afford them more leisure than with us. There is a strong and growing movement, so I was told, for a five-day week for all classes of workers, though I should hazard that, class for class, the men work longer hours per day than in Great Britain. Their leisure is never too scanty, however, to prevent their showering on the English traveller kindly and proverbial hospitality: it is impossible to acknowledge their friendliness to England too appreciatively.

New York abounds with interest for the visitor with scientific leanings-Columbia University, the Bell Telephone Laboratories, the National Broadcasting Co., the 'Long-Distance' building for telephone and radio-telephone circuits. Everywhere one experienced boundless keenness, enthusiasm, knowledgeability, and friendliness.

The two capital cities of Canada and the States well repay a visit. Ottawa, which is being subjected to a measure of replanning, occupies a site of great natural beauty. Among the recent buildings are the palatial National Research Laboratories which, finely situated on the bank of the Ottawa River, are playing an ever-increasing part in Canada's industrial affairs. Washington must surely be one of the most beautiful cities in the world, with its stately buildings and wide avenues bordering on the Potomac River and Park. White marble and Greek architecture are adhered to for public and Governmental buildings in the environs of the Capitol, among the more recent additions being the magnificent Supreme Court and the Folger Shakespeare Library with its replica of the old Globe Theatre. The dignified building of the National Academy of Sciences stages permanently a fine series of working exhibits of fundamental experiments, which the public eagerly frequents. Some four miles away is the National Bureau of Standards, sister institution to the National Physical Laboratory, and with many problems in common.

Western America provides a powerful magnet for the visitor, in the shape of the Canadian Rockies, the Yosemite Valley, the Big Trees, the National Parks, the Grand Canyon, and the gracious beauty of San Francisco where the delightful climate, sea fogs and western geniality make an Englishman feel thoroughly at home. At Berkeley, a few miles away, the University of California exemplifies the scale of grandeur on which so many of the American and Canadian universities have been established. Among much that is intriguing are the full-scale daily newspapers which the students control, finance, publish and edit at some of the universities. Berkeley rejoices in a fine campus and many magnificent buildings, including a Greek theatre holding 10,000 and a sports stadium for 90,000 . It is here that E. O. Lawrence by his genius and persistency has developed the cyclotron into the most potent practical contribution of recent times to the study of neutrons and artificial radioactivity. I refer to this again later. Thirty miles south at Palo Alto, is the Leland Stanford University, the buildings of which are most attractive with walls of buff-coloured sandstone and red-tiled roofs in the old Spanish mission style. Among much else of interest is a 2 million-volt transformer outfit, the insulating supports of which were braced with temporary steel strutting. This, I learnt on inquiry, was a precautionary measure in readiness for the next great earthquake, which was about due!

Los Angeles, that city of astounding growth and spacious conceptions, confronted with the problems of overcoming desert conditions, has solved them with gigantic irrigation schemes. Water is distributed lavishly : lawns are only kept alive by almost continuous sprinkling. Fruit is amazingly cheap. Here are the fine new buildings of the University of California, the University of Southern California, and the renowned and immense film studios of Hollywood, a eity which merges completely into Los Angeles. Near by is the 'Hollywood Bowl' a natural hillside auditorium capable of holding forty thousand people and possessing marvellous natural acoustics, which are reinforced by a large 'shell' reflector enabling those in the remotest seats 550 feet away to hear easily. The Bowl is famous for its "Symphonies under the Stars". The stable and agreeable climate enables outdoor social functions to be held with certainty.

Ten miles away near the hills is Pasadena, with its famous California Institute of Technology. Among much of interest is the Kellogg radiation laboratory where Dr. C. C. Lauritsen's pioneer work on super-voltage $\mathrm{X}$-ray therapy is being carried out. In another building one can see the process of grinding the 200 -inch reflector which, when completed in about two years' time, is intended for Mount Palomar, a hundred miles away, as the night glare of Los Angeles has grown to interfere with some of the work at Mount Wilson. Incidentally, there is now a magnificent road up to the 5,700-ft. summit of Mount Wilson, the journey by car from Pasadena taking about an hour, a very different state of things from that which prevailed a few years ago. The Observatory lays itself out to attract visitors, some twenty 
thousand attending the lectures and demonstrations during the year. A similar public response meets the efforts of the Observatory in Griffith Park, overlooking Los Angeles, visitors flocking to see the planetarium and astronomical working models.

While much of Chicago is drab and drear, the new and reclaimed portion on the shore of Lake Michigan is remarkably attractive. In September last at Chicago, the Fifth International Congress of Radiology, with some 2,800 members from forty nations, held its meetings and housed its members in a single hotel equipped with suitable convention halls and some two thousand bedrooms. Under the efficient presidency of Dr. A. C. Christie of Washington, several hundred papers were down for reading: they were dealt with by nine different sections, which met concurrently, apart from a few general sessions. The enthusiasm of members was catered for by programmes of meetings and educational courses which, together with intervals for sustenance, went on daily from 8 a.m. until midnight or after. Any unemployed moments could be devoted to a large scientific and industrial exhibition of apparatus. Many examples of shockproof high-voltage X-ray apparatus were on view, together with associated devices designed primarily for the study of neutrons and nuclear physics.

The radiophysics section was mainly devoted to the measurement and generation of very short wave radiation, that is, $\mathrm{X}$-rays generated by voltages of the order of a million volts, and radium gamma rays. Some of the papers were of extreme interest. As regards the production of very high voltages, America, always a pioneer in such matters, is now paying widespread attention to the use of supervoltages, not only for nuclear physics research, but also for X-ray therapy for cancer treatment. As against radium therapy, the arguments advanced are that it is not yet proved or ruled out that the shorter gamma rays have any clinical advantage over $\mathrm{X}$-rays, while the latter, though bearing higher maintenance charges, offer the advantages of a lower initial cost and the possibility of implanting greater depth doses in the body. There appeared, however, to be a considerable body of opinion which doubted whether there is as yet any sound clinical evidence which could establish a real superiority of million-volt X-ray therapy over, say, 200 or $400 \mathrm{kv}$. therapy.

Quite apart from the achievements of the highvoltage electrical engineer for commercial utilities, there have recently been developed for physical and clinical purposes a number of radically different methods for generating very high voltages: $(a)$ the super-tension transformer, $(b)$ the radiooscillator generator, $(c)$ the electrostatic generator of the belt type, $(d)$ the cyclotron.
Million-volt transformers of which some part or other of the high-voltage circuit is in the open air, are of necessity so large as to require a special building to house them; there are numerous examples operating X-ray tubes, neutron tubes, etc., mainly in the States, but also elsewhere. The principle of mounting both transformer and X-ray tube in a common oil tank has long been familiar, but it has now been extended to voltages of $400 \mathrm{kv}$. and upwards. In a recent development of high-voltage X-ray apparatus by Dr. Coolidge, only the earthed target-end of the tube emerges from the tank. The advantageous features of this type of outfit are the freedom from electrical dangers, the relatively small amount of lead protection required, the accessibility of the target, and, perhaps, most of all, the small space needed, the dimensions of the outfit being of the order of only a few feet. Recent-experiments on the replacement of transformer oil by compressed gaseous dielectrics are likely, it is anticipated, to lead to high-tension generators of even more modest dimensions.

Examples of radio-oseillator resonance X-ray generators, designed by Dr. D. H. Sloan, are to be found in New York and San Francisco. A shortwave radio oscillator sends its power into a highvoltage resonance coil mounted within a metal vacuum tank which serves as the $\mathrm{X}$-ray tube and which is continuously evacuated. The hot cathode is situated in the side of the tank directly facing the $\mathrm{X}$-ray target, which is mounted on the bottom of the coil where there is a voltage maximum, so that the high voltage is generated entirely within the X-ray tube precisely where it is to be used.

Electrostatic machines were largely used in the early days of X-rays, and the electrostatic highvoltage generator of the endless-belt type, which we owe to Van de Graaff, is virtually a large Holtz machine, consisting essentially of a rounded conducting terminal supported on an insulating column and charged by a swiftly moving $(4,000-$ 5,000 feet a minute) flat insulating belt (of rubberized fabric) conveying electricity 'sprayed' on the belt by corona points charged with 20,000 volts, and depositing it within the terminal. The outfit is robust and simple, and very high and steady voltages (several million) may be obtained. The current output is proportional to the speed and number of the belts and the dielectric strength of the surrounding medium, usually air. There are now a number of these installations in the States ; I saw an early type at the Carnegie Institution (Dept. of Terrestrial Magnetism) at Washington. This produces a million volts with regularity: the only uncertainty is occasioned by the high humidity which often occurs in Washington. This difficulty will be avoided in the new 5 million-volt 
apparatus which is being constructed, and which will operate at several atmospheres pressure within a large pear-shaped steel reservoir (some 60 or 70 feet high), mounted vertically on its small end. This outfit is designed for work on nuclear physics. Another outfit at the Huntington Memorial Hospital, Boston, operates a continuously pumped cascade X-ray tube at a million volts and up to three milliamperes; while yet another outfit, at the Massachusetts Institute of Technology, develops a steady voltage of five million and a current of two milliamperes in work on atomic disintegration.

The cyclotron was designed for use in the domain of atomic physics and, while it is inapplicable at present to X-ray purposes, it does, as already mentioned, render available for the biological worker and radiologist two powerful new tools, in the shape of artificial radioactive elements and neutrons. Some twenty-five outfits are at present under construction the world over, six or seven in the States and two in England (Cambridge and Liverpool).

The latest model of the cyclotron, which incidentally weighs 100 tons, utilizes the principle of multiple or 'cascade' acceleration of ions by a combination of a magnetic and a swiftly alternating electric field, and can so impart to a beam of protons or deuterons equivalent voltages up to $7 \frac{1}{2}$ million. If the beam is allowed to impinge on beryllium, a stream of neutrons results which may be some thousands of times more powerful than any other method can provide. For example, a beam of neutrons corresponding to $7 \frac{1}{2}$ million volts and 20 microamperes is stated to be equivalent to the gamma radiation from 100,000 grams of radium in equilibrium. The controls for the operator are remotely situated from the cyclotron, further protection being afforded by tanks of water three feet thick encircling the apparatus.

By the use of one or other of the three types of particle which the cyclotron provides in such abundance, virtually all the known elements have been made to yield radioactive isotopes through the method of nuclear bombardment. Among them is radio bismuth, which is identical with radium-E in every respect. In one day as much radio sodium (with a half-life of 15 hours) can be made as corresponds to $100 \mathrm{mgm}$. of radium. Some of the artificial radioactive elements are finding a revolutionary field of service as 'tracers' or 'tagged atoms' in biological and clinical research. For example, radio sodium, when drunk in a solution of common salt, manifests itself in the fingers of the hand in less than two minutes by the emission of gamma rays; the residue, magnesium, is quite innocuous within a few days.

Both in Berkeley and elsewhere the study of neutron therapy (on animals) is being taken up. Neutrons ionize in a manner very different from that of gamma or X-rays, and are unique in being more absorbable in body tissue than in bone. If the present claims of selective reaction to tumour tissue are substantiated, it would seem that neutrons may presently have high therapeutic significance.

Prof. Lawrence has under construction a special building for housing a much larger cyclotron, which has been designed expressly to generate radioactive elements for prosecuting bio-physical and medical research. The new outfit, which will weigh 220 tons, is expected to afford voltages equivalent to 10 million, and to give five or ten times the yield of the present cyclotron.

It is the practice of the International Radiological Units and Protection Committees to meet on the occasions of the International Congress. The chief business before the Units Committee, which met under the chairmanship of Dr. Failla of New York, was to determine whether or not the time had come when the röntgen - the ionization unit of X-ray quantity--should also be used for very high-voltage rays and radium gamma rays. The British delegates (Dr. N. S. Finzi, Prof. F. L. Hopwood and Dr. G. W. C. Kaye) presented a memorandum from the British X-ray Units Committee, which advocated the step and with it an appropriate modification of the present definition of the röntgen. In the end, the important step was taken and a generalized definition was agreed provisionally until the next Congress, when it was anticipated that a still more general definition embracing all classes of radiation may be forthcoming. The röntgen is now defined as follows : "The röntgen (symbol r) shall be the quantity of $\mathrm{X}$ - or gamma-radiation such that the associated corpuscular emission per $0.001293^{*}$ gramme of air produces, in air, ions carrying 1 electrostatic unit of quantity of electricity of either sign."

The International Protection Committee, which met under the chairmanship of Dr. Kaye, made a number of changes in the existing recommendations, particularly in relation to the new problems of protecting operators working with super-voltage $\mathrm{X}$-rays or radium 'bombs' containing large quantities of radium. Many of the data utilized were based on recently published results of the National Physical Laboratory.

It was announced during the Congress that the next meeting would be held in Berlin in 1940 under the presidency of Dr. Holthusen of Hamburg. It will be governed by a new set of rules and regulations adopted at Chicago, largely through the energy and initiative of Dr. Christie.

* 0.001293 gramme is the mass of 1 c.c. of dry atmospheric air at $0^{\circ} \mathrm{C}$., and $76 \mathrm{~cm}$. of mercury pressure. 